\title{
A relevância da ISO 9001:2008 para o usuário do transporte coletivo de Curitiba
}

(The ISO 9001:2008 relevance for public transit user in Curitiba)

Jian Cloud Toniazzo*

Leandro Gonçalves Moreno**

Willian Alves dos Santos***

\section{Resumo}

A norma NBR ISO 9001:2008 estabelece requisitos em um sistema de gestão buscando foco na qualidade para o cliente e melhoria contínua nos processos, sendo estabelecida em empresas não só por garantir tal características, mas também como pré-requisito em uma cadeia produtiva de um processo ou até mesmo em propósitos publicitários e de autopromoção. Diante do real objetivo e foco da certificação, que é o cliente, e sustentado por indicadores de piora na qualidade do transporte, este artigo tratará sobre qual é a relevância da certificação para o usuário do transporte coletivo de Curitiba, especificamente nas linhas de ônibus certificadas que atendem aos redores do Setor de Educação Profissional e Tecnológica - SEPT da Universidade Federal do Paraná. Esta relevância foi estimada por meio de uma pesquisa Survey, envolvendo questionamentos sobre o conhecimento da norma, da certificação das empresas, tal como de uma avaliação geral da qualidade do transporte prestado. Os resultados, por sua vez, descreveram um desconhecimento da norma, tal como uma indiferença da certificação para a qualidade, avaliada também de forma negativa.

\section{Palavras-Chave: NBR ISO 9001:2008; Qualidade; Foco Cliente; Melhoria Contínua; Transporte Coletivo.}

\begin{abstract}
NBR ISO 9001:2008 establishes requirements for a quality management system, aiming focus on quality and continuous improvement of customer's processes, being established in companies that not only search for these characteristics, but also as a pre requisite of a production in a supply chain's process or even self-promotion and advertising purposes, for an example. Looking for the real purpose and focus about the certification, which is the customer, and supported by indicators of a bad quality of transport, this article will expose about what is the relevance of the certification for the user of public transit in Curitiba, specifically on certified companies bus lines that serve the Professional and Technological Education Department - SEPT in Federal University of Paraná. This relevance was estimated by means of a Survey's research, involving questions about the knowledge of the standard, the companies' certification, and a general assessment of the quality in the transport service. The results described a non-understanding certification's objectives, as an indifference fact about certification for quality, assessed negative way too.
\end{abstract}

Keywords: NBR ISO 9001:2008; Quality; Customers Focus; Continuous Improvement; Public's 
1. Introdução

A Norma ABNT NBR ISO 9001: 2008 especifica requisitos para um sistema de gestão da qualidade em que uma organização: a) Necessita demonstrar a sua aptidão para, de forma consistente, proporcionar produto que vá ao encontro dos requisitos do cliente, estatutários e regulamentares aplicáveis; b) Visa aumentar a satisfação do cliente através da aplicação eficaz do sistema, incluindo processos para melhoria contínua, tal como garantir a conformidade com os requisitos do cliente, estatutários e regulamentares aplicáveis. ABNT NBR ISO 9001 (2008) tratada de agora em diante de forma abreviada como ISO.

Os princípios da gestão da qualidade, na qual a ISO se inspira são: total satisfação dos clientes; gerência participativa; desenvolvimento de recursos humanos; constância de propósitos; aperfeiçoamento contínuo do sistema (kaizen); gestão e controle de processos; disseminação de informações; gestão das interfaces com agentes externos; delegação; assistência técnica e garantia da qualidade. OLIVEIRA (2004) corrobora tal afirmação.

Já fatores como confiabilidade, velocidade, custos e segurança são essenciais para um sistema de transporte coletivo, pois a flexibilidade e evolução contínua das cidades leva em conta que tais fatores tornam-se questões estratégicas que não podem ser desconsideradas dadas as possíveis consequências futuras, conforme LOMBARDO (2010).

Nas grandes cidades, o transporte coletivo urbano também tem a função de proporcionar uma alternativa de transporte em substituição ao automóvel, visando a melhoria da qualidade de vida da comunidade mediante a redução da poluição ambiental, congestionamentos, acidentes de trânsito, necessidade de investimentos em obras viárias caras, consumo desordenado de energia, etc. FERRAZ \& TORRES (2004) serve de base para tal perspectiva.

Já a detentora da gestão do transporte coletivo na capital do Estado do Paraná traça como objetivos e metas de sua gestão a fim de melhorar a vida urbana, facilitando os deslocamentos e assegurando o acesso das pessoas às suas casas, ao trabalho, aos serviços e ao lazer. Essa é a meta que a URBS - Urbanização de Curitiba S/A, podendo ser tratada somente como URBS, tem como desafio diário à qualidade de empresa responsável pelas ações estratégicas de planejamento, operação e fiscalização que envolvem o serviço essencial 
de transporte público e serviços de transporte comercial, escolar, táxi e moto frete, além do gerenciamento e administração de equipamentos urbanos de uso comercial da cidade, o que afirma URBS (2013b).

Fomentado por indicadores que não demonstram uma melhora na qualidade do transporte coletivo na capital do Estado do Paraná, como se verá no item 2.3, em comparação a anos anteriores, assim como na real proposta da ISO em certificar e garantir a eficácia, eficiência e melhoria contínua na qualidade dos processos da organização tal como o fruto para os clientes que a utilizam, realizou-se uma pesquisa de satisfação que trata da relevância da ISO para o usuário do transporte coletivo de Curitiba, discorrendo sobre a relação da certificação de qualidade obtida pelas empresas do transporte coletivo de Curitiba com a satisfação dos clientes que utilizam este transporte. Desta forma, analisou-se, de forma geral: as óticas dos clientes, usuários do transporte coletivo sobre a ISO; o sistema de transporte público de Curitiba, funcionamento e sistema de gestão e panorama atual do sistema.

Munidos dos valores obtidos com a pesquisa, uma análise foi realizada, de forma específica: sobre o conhecimento dos usuários quanto a certificação; a relação do fato das empresas prestadoras de serviço possuírem tal certificação; a relevância para o usuário desta certificação na qualidade do transporte público e a satisfação dos usuários em relação a qualidade do transporte coletivo prestado nas linhas pesquisadas.

\section{Fundamentação Teórica}

\subsubsection{ISO: Ótica da Organização}

Segundo PALADINI (2012) na área de serviços não há como separar nitidamente o processo produtivo da prestação de serviços, pois ambos se confundem. Por isso, na gestão da qualidade, a empresa deve centrar-se, fundamentalmente, na interação com o usuário.

O setor de transporte público de passageiros exerce papel fundamental de integração do tecido urbano, afetando diretamente a produtividade das demais atividades econômicas em função da sua própria qualidade e produtividade. Assim, a qualidade do serviço prestado deve ser melhorada, já que existe uma ligação intrínseca entre o transporte coletivo urbano e a qualidade de vida de seus usuários conforme afirmam FERNANDES \& BODMER (1995). 
De acordo com SILVA (2011), nos últimos anos a sociedade e os clientes em especial tem evidenciado preocupações em relação ao desempenho dos produtos/serviços adquiridos. Estas preocupações obrigam as organizações em repensar as suas estratégias atribuindo uma maior relevância às normas da qualidade. A certificação de acordo com a norma ISO é um reconhecimento atribuído às organizações que assegura a conformidade dos seus produtos e/ou serviços, satisfação dos seus clientes e a melhoria contínua dos processos.

Dessa forma, a relação da produção de serviços com a gestão da qualidade se apoia em algumas considerações: a produção e o consumo são simultâneos, de tal modo que não há como precisar o início de um e o término do outro; os processos produtivos devem ser flexíveis e adaptáveis a momentos, situações, contextos, etc.; as ações devem ser direcionadas ao maior contato com os clientes, definição de seus interesses, preferências, exigências e necessidades que possam ser relevantes na hora de produzir o serviço, onde corrobora PALADINI (2012).

A certificação ISO para as empresas prestadoras de serviço servem de pré-requisito para realizar suas atividades ao seu cliente, que é a URBS, no qual é responsável pela gestão das empresas prestadoras, ou seja, a URBS não é certificada pela ISO, mas sim as empresas prestadoras do serviço e subordinadas a ela, URBS (2013b) assim assevera. Porém, afirmado pelas próprias empresas prestadoras do serviço, em exemplo a VIAÇÃO CIDADE SORRISO LTDA (2013) e VIACÃO TAMANDARÉ LTDA (2013) - Empresas certificadas e prestadoras do serviço de transporte nas linhas atendidas aos redores do SEPT concordam que, diante de suas Missões, Valores e Objetivos o foco de seu trabalho é a satisfação do cliente e melhoria contínua no processo. Sendo assim, tratamos como o real cliente o próprio usuário, e não a empresa administradora.

Como a ISO exige, as empresas prestadoras possuem atendimento aos requisitos tais como: procedimentos documentados, manual da qualidade, registros da qualidade, tratativa de não-conformidades, análise crítica em ações corretivas e preventivas, canais de relacionamento com o cliente entre outros, estabelecidos pela ABNT NBR ISO 9001 (2008). 


\subsubsection{A ISO na Ótica do Cliente}

O objetivo da ISO especifica requisitos para um sistema de gestão da qualidade em que uma organização: a) necessita demonstrar a sua aptidão para, de forma consistente, proporcionar produto que vá ao encontro dos requisitos do cliente, estatutários e regulamentares aplicáveis; b) visa aumentar a satisfação do cliente através da aplicação eficaz do sistema, incluindo processos para melhoria contínua do sistema e para garantir a conformidade com os requisitos do cliente, estatutários e regulamentares aplicáveis.

Por outro lado, os clientes de empresas prestadoras de serviços se utilizam de cinco dimensões para fazer seu julgamento quanto a sua qualidade, conforme classifica FITZSIMMONS (2005). São eles: confiabilidade: refere-se à prestação do serviço prometido com confiança e exatidão, ou seja, um serviço que atenda à expectativa do cliente e o prazo cumprido; responsabilidade: quando ocorre uma falha no serviço, a empresa tem a capacidade de se recuperar imediatamente e com profissionalismo, a fim de que o cliente crie uma percepção positiva da qualidade; segurança: refere-se ao conhecimento e a cortesia dos funcionários, assim como sua capacidade de transmitir confiança e confidencialidade; empatia: é a demonstração de interesse, atenção personalizada aos clientes, isto é, o esforço da empresa para entender as necessidades dos clientes; e, por fim, aspectos tangíveis: é a aparência das instalações físicas e equipamentos, no caso deste trabalho, o ônibus. A condição ambiental, como a limpeza, é uma evidência tangível de cuidados daqueles que prestam serviços. A produção do serviço, no caso do serviço de transporte, deverá atender às necessidades da demanda, ou seja, daqueles passageiros da região e sua realidade, também segundo FITZSIMMONS (2005).

Apesar da certificação ter foco único e exclusivo na qualidade do produto/serviço oferecido ao cliente, ao longo do desenvolvimento deste trabalho não foram encontrados artigos, materiais ou textos que referem as opiniões dos usuários ou dos clientes que utilizam produtos ou serviços de empresas certificadas pela ISO, em especial de transporte coletivo.

A qualidade envolve diferentes conceitos, que vão desde a liderança até os meios de controle nos processos produtivos, sejam estes de manufatura ou de serviços. Uma evolução no conceito de qualidade veio com a necessidade de incorporar os diversos interesses dos 
stakeholders de uma organização na busca da excelência em desempenho. Afirmam CARVALHO e PALADINI (2005), tal como MORAES, FRANCO \& SOUZA (2011).

São dois pontos que se podem discorrer quanto a isso: o primeiro é que as empresas não possuem a noção do quanto e como esta certificação está alcançando a satisfação do cliente, diante da falta de materiais dedicados nesta visão e se estes resultados estão sendo alcançados. O segundo ponto é que podemos abrir um campo de pesquisa e estudo, tratando de mensurar se estas certificações estão atingindo de forma eficaz e eficiente o cliente final.

\subsection{O transporte público de Curitiba}

Para VASCONCELLOS (2006) o transporte é uma atividade necessária à sociedade e produz uma grande variedade de benefícios, possibilitando a circulação das pessoas e das mercadorias utilizadas por elas e, por consequência, a realização das atividades sociais e econômicas desejadas. No entanto, este transporte implica em alguns efeitos, os quais chamamos de impactos.

Sob este aspecto, o transporte coletivo torna-se de suma importância para o processo de gerenciamento da cidade. Um modelo adequado permite minimizar congestionamentos, emissão de poluentes, reduzir acidentes de trânsito, bem como proporcionar uma significativa melhoria na qualidade de vida de seus cidadãos, conclui LOMBARDO (2010).

A Rede Integrada de Transporte - RIT, de acordo com URBS (2013b), permite ao usuário a utilização de mais de uma linha de ônibus com o pagamento de apenas uma tarifa. $\mathrm{O}$ processo de integração ocorre a partir de terminais de integração onde o cidadão pode desembarcar de uma linha e embarcar em qualquer outra dentro daquele espaço sem um novo pagamento. Assim, o usuário pode compor o seu próprio trajeto para se deslocar por diversos bairros de Curitiba e municípios da Região Metropolitana. Ao todo, são 14 cidades interligadas por esta rede de linhas que proporciona ampla mobilidade a mais de 2 milhões de pessoas 
As características e tipos de linhas que compõem a RIT são:

- Expresso Ligeirão: são operadas por veículos biarticulados de $28 \mathrm{~m}$ na cor azul, com número reduzido de paradas. Proporcionam deslocamentos mais rápidos. Embarque e desembarque são feitos em nível em Terminais e Estações Tubo;

- Expresso: são operadas por veículos tipo biarticulados, na cor vermelha que ligam os terminais de integração ao centro da cidade, através das canaletas exclusivas. Embarques e desembarques são feitos em nível nas estações tubo existentes no trajeto;

- Linha Direta: operam com veículos tipo padrão, na cor prata, com paradas em média a cada $3 \mathrm{~km}$, com embarque e desembarque em nível nas estações tubo.

- Interbairros: São operados por veículos tipo padrão ou articulados, na cor verde, que ligam os diversos bairros e terminais sem passar pelo centro;

- Alimentador: são operadas por veículos tipo micro, comum ou articulados, na cor laranja, que ligam terminais de integração aos bairros da região;

- Circular Centro: operadas com veículo tipo micro-ônibus, atende os principais pontos atrativos da região central de Curitiba.

- Convencional: operam com veículos tipo micro ou comum, na cor amarela, que ligam os bairros ao centro, sem integração.

- Interhospitais: liga os principais hospitais e laboratórios em um raio de 2,5 $\mathrm{Km}$ da área central, com saídas da Rodoferroviária;

- Linha Turismo: Com saída do centro, passa pelos principais parques e pontos turísticos da cidade.

- SITES: Sistema Integrado de Transporte do Ensino Especial. Atende aos alunos da rede de escolas especializadas para deficientes físicos e/ou mentais de Curitiba.

De acordo com a lei $\mathrm{n}^{\mathrm{o}}$ 12.597, de 24 de março de 2008, conforme CURITIBA (2008), compete a URBS a regulação, o gerenciamento, a operação, o planejamento e a fiscalização do Sistema de Transporte Coletivo de Passageiros do Município de Curitiba - PR. A partir do Convênio firmado com o Governo do Estado do Paraná em 1996, a URBS assumiu as mesmas funções no âmbito do transporte coletivo metropolitano, URBS (2013a) onde, dentro de suas atribuições estão: contratar as empresas operadoras; definir itinerários, pontos de paradas e horários; determinar tipos e características dos veículos; vistoriar a frota e fiscalizar 
os serviços; calcular tarifa técnica; controlar a quilometragem rodada e passageiros; gerenciar o Cartão Transporte. A operação do sistema é executada por empresas privadas, através de concessão. De acordo com URBS (2013b), compete às empresas operadoras / consórcios, dentre outras atribuições: adquirir a frota de ônibus de acordo com as determinações da URBS; contratar e remunerar pessoal de operação (motoristas, cobradores, etc.); manutenção e limpeza dos veículos e; executar as ordens de serviços encaminhadas pela URBS.

\subsection{Panorama atual do transporte público}

Pesquisa realizada por TRISOTO (2012) mostra que 54\% dos brasileiros enfrentam mais de um congestionamento por dia e a maioria acredita que o problema deve piorar nos próximos cinco anos, com o aumento da circulação de veículos e os eventos internacionais a serem realizados no país, a exemplo da Copa do Mundo e da Olimpíada. Na mesma linha, segundo o Departamento de Trânsito do Paraná - DETRAN/PR, a frota da capital do Estado cresceu 4,65\% em um ano, passando de 1.210.839 veículos, em março de 2011, para

1.267.261 em março de 2012. O crescimento implica em mais carros circulando ao mesmo tempo, o que causa lentidão em determinados pontos.

Ainda de acordo com TRISOTO (2012), especialistas, como o professor do curso de mestrado e doutorado em Gestão Urbana, Trânsito e Urbanismo da PUCPR, Clovis Ultramari, apontam duas soluções prioritárias: investimento em transporte coletivo de qualidade e diversificação nos horários de saída de empresas e escolas, por exemplo. "Ainda é mais interessante passar duas horas preso em um carro do que usar o ônibus. O carro é confortável, te leva para onde você quiser e ainda proporciona privacidade", argumenta.

No final de 2010, MORAES (2011) avalia o fato do transporte público ser concedido à iniciativa privada, tendo como justificativa a melhora na prestação do serviço em cinco itens previstos em edital: cumprimento de viagens no horário; satisfação do usuário com veículos e operadores; interrupção de viagens por falha; liberação de vistoria; e número de autuações diminuídas. Mesmo assim, apenas 35\% dos usuários afirmaram terem percebido alguma melhora no transporte coletivo de Curitiba. $12 \%$ dos entrevistados afirmaram que piorou e os demais disseram não ter observado nenhuma mudança. 
Em soma, AZEVEDO (2011) relata que o Índice de Passageiros por Quilômetro - IPK da região metropolitana de Curitiba caiu $21 \%$ na última década, a maior queda entre as dez capitais brasileiras monitoradas. AZEVEDO (2011) também afirma que, segundo o DIEESE, o IPK é importante porque influi diretamente no preço da passagem. Quanto menor o índice, mais cara é a tarifa. Em Curitiba a queda no IPK é registrada há quase duas décadas. Entre 1994 e 2001, a quilometragem aumentou 58\%. No mesmo período, houve um crescimento de apenas $2 \%$ no números de usuários. O IPK caiu e a passagem aumentou.

UECHI (2002) defende que as empresas necessitam assegurar qualidade devido à competitividade presente em todos os ramos de atuação, devendo ela estar presente nos produtos, na agilidade, na eficácia e ainda por cima com custos compatíveis.

\subsection{Metodologia de Pesquisa e Coleta de Dados}

A pesquisa Survey pode ser descrita como a obtenção de dados ou informações sobre características, ações ou opiniões de determinado grupo de pessoas, indicado como representante de uma população alvo, utilizando um questionário como instrumento de pesquisa, dado por FONSECA (2002).

Foi realizada a pesquisa e coleta de dados baseado na metodologia Survey, com um questionário estruturado e fechado, onde foram questionados os seguintes itens:

1. Conhecimento da existência da certificação ISO pelo entrevistado;

2. Ciência do fato que as empresas prestadoras do serviço são certificadas;

3. Relevância ou não, da certificação ISO para a qualidade do serviço prestado pelas empresas;

4. Classificação de 1 a 6 (1 Pior e 6 Melhor) dada pelo entrevistado, para a qualidade do serviço de transporte público;

5. Quantidade de dias por semana em que o usuário utiliza as linhas de transporte.

6. A principal linha da região que o usuário utiliza;

7. Principal motivo da utilização do transporte. 


\subsubsection{Nicho de pesquisa}

A pesquisa foi realizada entre os dias 12 a 15 de março de 2014, em horários matutinos, vespertinos e noturnos, nas imediações do SEPT localizado na rua Doutor Alcides Vieira Arcoverde, Jardim das Américas, Curitiba - PR. Tendo como escopo as linhas de ônibus e empresas prestadoras: INTERBAIRROS V (Tipo interbairros); ESTUDANTES (Tipo convencional) e ERASTO GAERTNER (Tipo convencional).

\section{Resultados Obtidos}

Foram entrevistadas 129 pessoas nas datas de 12 a 15 de março de 2014, e como descrito no nicho de pesquisa, foram coletadas as informações, em diversos horários e períodos, focando nas principais linhas atendidas pelo SEPT:

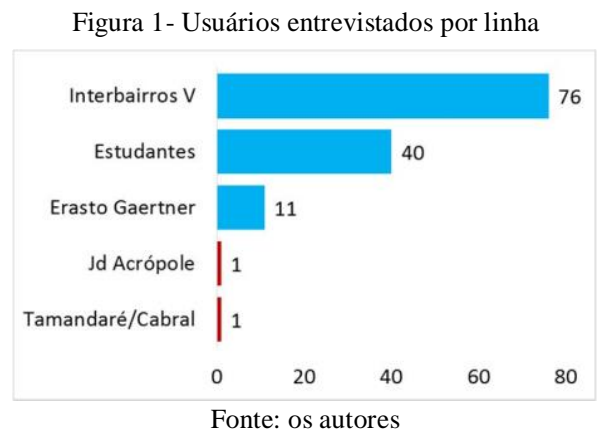

Conforme Figura 1, houve dois usuários que informaram linhas de ônibus que não fazem parte do escopo de pesquisa, entrevistas estas que foram descartadas das análises. $\mathrm{Na}$ sua absoluta maioria, os usuários entrevistados utilizam o transporte coletivo como meio de locomoção para fins de estudo ou de trabalho, tal como a quantidade de dias de utilização é de sua grande maioria quatro dias da semana ou mais, vistos respectivamente na Figura 2:

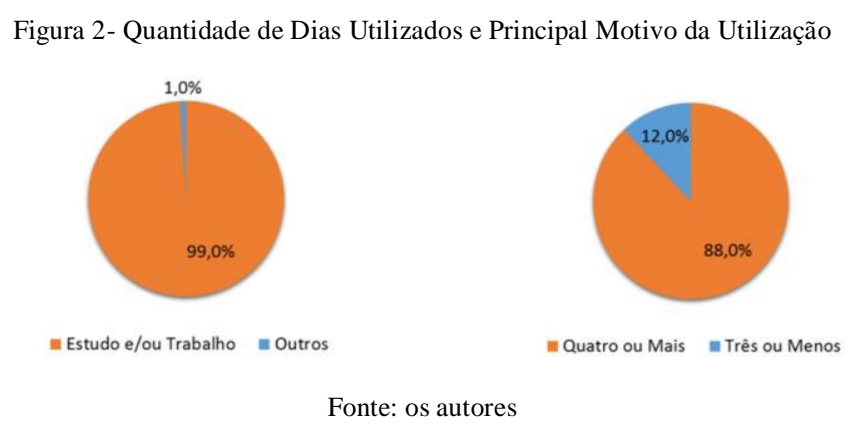


No primeiro questionamento aos entrevistados, foi indagado se a pessoa possuía o conhecimento da certificação ISO. Os resultados apontaram que uma leve maioria dos usuários desconhecem a certificação. Trata-se esse conhecimento como um entendimento básico da norma, mostrado na Figura 3:

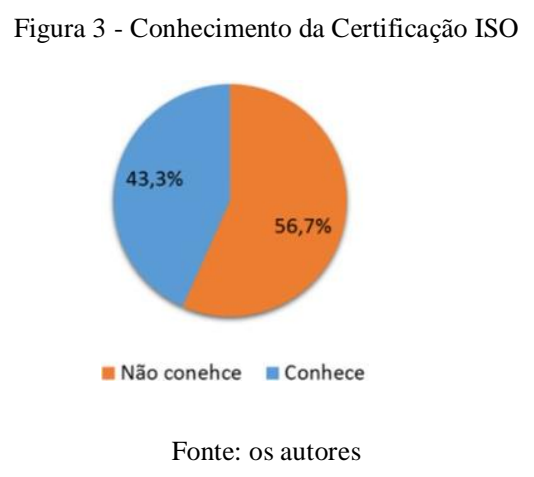

Quanto ao conhecimento dos usuários acerca da certificação das empresas prestadoras, a Figura 4 mostra que 35,4\% dos entrevistados sabem que as empresas prestadoras de serviço de transporte coletivo em Curitiba são certificadas pela ISO. Já 26,7\% destes $35,4 \%$ não sabem do que se trata a norma e sabe que as empresas são certificadas apenas por conta do selo que é colocado nos coletivos, ou seja, apenas $25,9 \%$ dos entrevistados sabem que as prestadoras são certificadas e tem noção do que trata a norma:

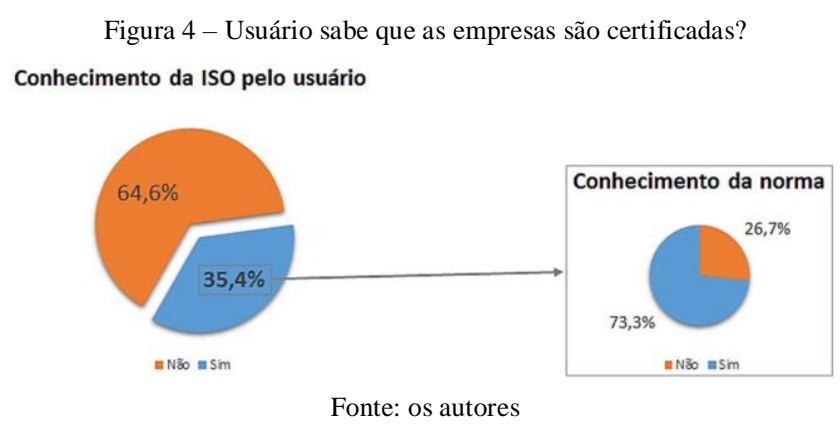

Em consequência de um desconhecimento da norma, da certificação das empresas, no propósito de seu principal objetivo no cumprimento da satisfação do cliente e melhoria contínua, tal como guiado por indicadores de insatisfação e piora na qualidade do serviço prestado, a grande maioria dos usuários do transporte público de Curitiba não acha relevante a certificação ISO nas empresas prestadoras do serviço, conforme figura 5: 
Figura 5 - Usuário considera relevante a ISO?

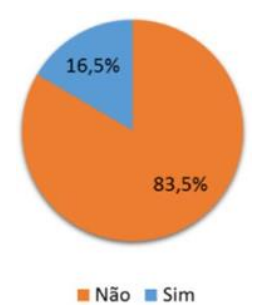

Fonte: os autores

Em uma análise das linhas de ônibus separadamente, conclui-se uma relevância maior da certificação entre os usuários que utilizam a linha Estudantes (Tipo Convencional):

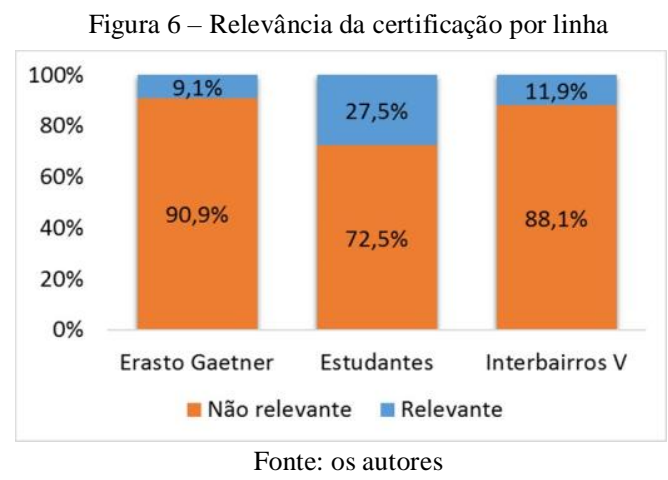

Quando analisadas as médias das notas dadas pelos usuários ao serviço, aqueles que acham relevante a certificação aferiram uma nota na qualidade do serviço prestado maior em relação aos usuários que não consideram relevante. Por fim, a média geral dos usuários mostra um nível regular de avaliação das empresas.

Quadro 07 - Média de classificação da qualidade do serviço

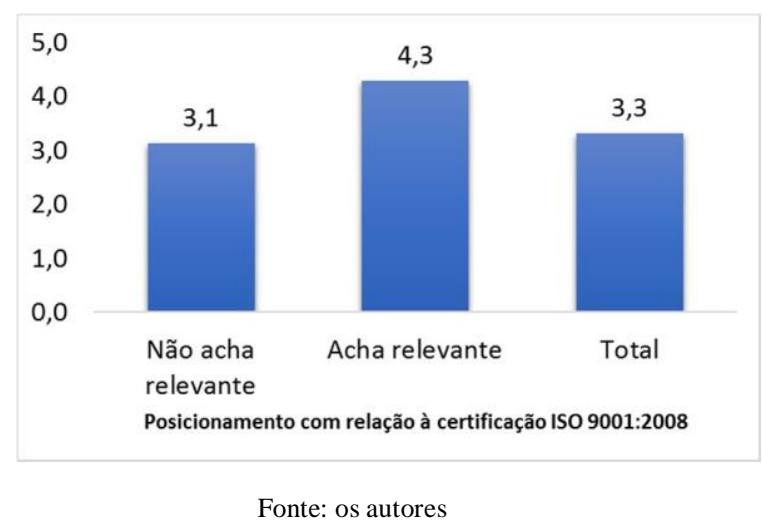




\section{Considerações Finais}

Conclui-se, após a análise de todos os aspectos levantados nos objetivos deste trabalho, gerais e específicos, e com o levantamento feito por meio das pesquisas de campo, que, no contexto da amostra, a irrelevância da ISO é notória por parte do usuário do transporte coletivo de Curitiba, não o atingindo da forma necessária e não havendo uma percepção da diferença entre estar certificado ou não em termos práticos. Esta constatação torna ainda mais pertinente o fator da validação da norma servir pura e simplesmente como pré-requisito para a operação do sistema frente à URBS, aliado ao fator de que a autopromoção via exposição dos "Selos de Qualidade" nos ônibus é ineficaz e ineficiente. Não faz sentido promover algo que, por desconhecimento, não se pode avaliar. Os resultados desse desconhecimento são nítidos, $64,6 \%$ sequer sabem da ISO nas empresas de transporte coletivo no contexto deste trabalho.

Percebe-se uma relação 80/20 no questionamento principal, que trata da relevância da ISO para o usuário. Cerca de $20 \%$ dos usuários acham relevante a certificação, em análise de Pareto, isso representa que $80 \%$ não reconhecem a ISO como algo importante. A relevância é maior nos usuários da linha Estudantes (Tipo Convencional), o que pode ocorrer por conta de fatores como número de passageiros menor em relação aos outros, grau de instrução do indivíduo ou quantidade de ônibus ofertadas de modo diferenciado as outras linhas.Tal perspectiva é corroborada por uma média relativamente baixa na avaliação do transporte coletivo, nota 3 de 6 . Há uma melhora de percepção positiva entre os que reconhecem a certificação como algo relevante na forma de avaliar a qualidade do serviço prestado.Levantase também uma discussão quanto às certificadoras da norma, e sua definição do escopo frente a uma validação do sistema de gestão. O cliente real, como citado neste artigo, e sua satisfação é determinante na manutenção e/ou validação?

Por fim, os próximos passos que poderão ser seguidos em trabalhos mais densos devem envolver a relevância da ISO para as empresas prestadoras da URBS, tal como uma visão gerencial da detentora do transporte coletivo da capital do Estado, aliado aos propósitos de certificação e de auditoria das empresas certificadoras. Estes estudos podem dar um panorama maior sobre a norma em seu contexto real, e as diversas faces que assume em variados pontos de um fluxo processual (do prestador de serviço até o cliente e seu impacto social). 


\section{Referências Bibliográficas}

ABNT - ASSOCIAÇÃO BRASILEIRA DE NORMAS TÉCNICAS. NBR ISO 9001:2008: Sistemas de gestão da qualidade - Requisitos. Rio de Janeiro: ABNT, 2008. 30 p.

AZEVEDO, Gabriel. Curitiba perde mais passageiros por quilômetro: Blog "Fure o Tubo". Pesquisa e Dados DIEESE, FIPE, e Gazeta do Povo, 2011. Disponível em: $<$ http://fureotubo.wordpress.com/2011/06/25/curitiba-perde-mais-passageiros-porquilometro/>. Acesso em: 16 ago. 2013.

CARVALHO, M. M; PALADINI, E. P. Gestão da qualidade: teoria e casos. Rio de Janeiro: Campus, 2005;

CURITIBA (Município). Lei $\mathbf{n}^{\mathbf{0}} \mathbf{1 2 . 5 9 7}$, de 24 de março de 2008. Dispõe Sobre A Organização do Sistema de Transporte Coletivo da Cidade de Curitiba. Curitiba, PR.

FERNANDES, Fátima Sobral e BODMER, Milena. Gestão empresarial da qualidade nos transportes: aproximação entre teoria e prática. Revista dos Transportes Públicos - ANTP, São Paulo, ano 18, p. 33-43, 4º Trimestre 1995.

FERRAZ, Antonio Clovis Pinto; TORRES, Isaac Guillermo Espinoza. Transporte público urbano. São Paulo: Rima, 2001. 367 p.

FITZSIMMONS, James A. Administração de Servicos. 2005. ed. São Paulo: Bookman, 2005. 564 p.

FONSECA, J. J. S. Metodologia da pesquisa científica. Fortaleza: UEC, 2002. Apostila.

GOETTEN, Carolina. Deficiências do transporte coletivo fazem curitibano preferir o carro, diz especialista: Revista Carta Maior. Pesquisa e Dados UFPR, PUC PR, DETRAN PR, 2012. Disponível em: <http://www.cartamaior.com.br/?/Editoria/Politica/Deficienciasdo-transporte-coletivo-fazem-curitibano-preferir-o-carro-diz-especialista/4/24668>. Acesso em: 18 ago. 2013.

KRÜGER, Joel. Piora do trânsito em Curitiba acende alerta: Cidade precisa de metrô: Matéria Globo Universidade, 2013. Pesquisa e Dados pela MapLink. Disponível em: <http://redeglobo.globo.com/globouniversidade/noticia/2013/06/piora-do-transito-emcuritiba-acende-alerta-cidade-precisa-de-metro.html>. Acesso em: 04 ago. 2013.

LOMBARDO, Adilson. Canaletas Exclusivas de Transporte Coletivo: Impactos Sobre A Mobilidade Urbana De Curitiba. 2010. 99 f. Dissertação (Mestrado) - Curso de Engenharia de Produção, Departamento de Centro Tecnológico, Universidade Federal de Santa Catarina, Florianópolis, 2010.

MORAES, Vanda. Usuários não percebem mudança no transporte público de Curitiba: SindiUrbano PR. Pesquisa e Dados Paraná Pesquisas e Gazeta do Povo, 2011. Disponível em: $\quad$ http://www.sindiurbano.org.br/home/48-destaques/449-transportepublico.html>. $\quad$ Acesso em: $16 \quad$ ago. 
MORAES, Paulo Eduardo Sobreira, FRANCO, Maura Regina e SILVA Guilherme R. S. Souza e - Ensaio sobre a insustentável leveza do conceito de Qualidade - Revista Qualidade Emergente, 2010, v.1 n.1: 3-12;

OLIVEIRA, O. J. Introdução à história e fundamentos. In: OLIVEIRA, O. J. (org.). Gestão da qualidade: tópicos avançados. São Paulo: Pioneira Thomson Learning, 2004;

OLIVEIRA, O. J.; MELHADO, S. B. Nova norma ISO 9000 versão 2000. In: OLIVEIRA, O. J. (org.). Gestão da qualidade: tópicos avançados. São Paulo: Pioneira Thomson Learning, 2004;

PALADINI, Edson Pacheco. Gestão da Qualidade: Teoria e Prática. 3. ed. São Paulo: Atlas, 2012. $339 \mathrm{p}$.

SILVA, Edna Lúcia da - Metodologia da pesquisa e elaboração de dissertação/Edna Lúcia da Silva, Estera Muszkat Menezes. - 4. ed. rev. atual. - Florianópolis: UFSC, 2005. 138p;

TRISOTO, Fernanda. Curitiba está cada vez mais lenta: Matéria Gazeta do Povo, 2012. Pesquisa e Dados pela Location \& Commerce e DETRAN PR. Disponível em:

<http://www.gazetadopovo.com.br/vidaecidadania/conteudo.phtml?id=1254037>. Acesso em: 04 ago. 2013.

UECHI, C. S. A visão que vem do alto. In: STURRION, W. A visão que vem do alto. Banas Qualidade. São Paulo: Epse, ano XI, nº 122, p.28-38, jul. 2002.

URBS, Urbanização de Curitiba S/A - Relatório de Gestão Organizacional, 2012. Disponível em: 〈http://www.urbs.curitiba.pr.gov.br/institucional/relatorio-gestao>. Acesso em: 27 jul. 2013a.

URBS, Urbanização de Curitiba S/A. Rede Integrada de Transporte - RIT, 2013. Disponível em: <http://www.urbs.curitiba.pr.gov.br/transporte/rede-integrada-detransporte>. Acesso em: 05 jul. $2013 \mathrm{~b}$.

VASCONCELlOS, Eduardo Alcântara de - Transporte e Meio Ambiente: Conceitos e informações para a análise de impactos. São Paulo: Ed. Do Autor, 2006.

VIAÇÃO CIDADE SORRISO LTDA (Curitiba). Institucional: Certificação ISO 9001:2008. 2013. Disponível em: 〈http://www.vcsorriso.com.br/institucional/\#certificacao $>$. Acesso em: 18 ago. 2013.

VIAÇÃO TAMANDARÉ LTDA. Certificação ISO 9001:2008. 2013. Disponível em: <http://www.viacaotamandare.com.br/iso.html>. Acesso em: 16 ago. 2013. 